\title{
Evaluation of Flow Cytometry and Kleihauer Techniques for Quantification of Fetomaternal Hemorrhage: A Prospective Cohort Study in Southwestern Iran
}

\author{
Zeinab Keshavarzi,2, Leili Moezzi ${ }^{1}$, Reza Ranjbaran${ }^{1}$, Abbas Behzad-Behbahani ${ }^{1}$, Masooma Abdullahi ${ }^{1}$, \\ Mahdokht Mahmoodi ${ }^{1}$, Sedigheh Sharifzadeh ${ }^{*}$ \\ 'Diagnostic Laboratory Sciences and Technology Research Center, School of Paramedical Sciences, Shiraz University \\ of Medical Sciences, Shiraz, Iran \\ ${ }^{2}$ Student Research Committee, Shiraz University of Medical Sciences, Shiraz, Iran
}

*Corresponding Author: Sedigheh Sharifzadeh, Ph.D. in Immunology, Associate Professor, Diagnostic Laboratory Sciences and Technology Research Center, School of Paramedical Sciences, Shiraz University of Medical Sciences, Shiraz, Iran. Tel: +98-713-2289113, Email: sharifsd@sums.ac.ir

Received May 17, 2018; Accepted September 25, 2018; Online Published October 20, 2018

\begin{abstract}
Background: Quantification of fetal red blood cells (RBCs) in maternal blood is of great importance to calculate appropriate dose of post-deliver anti $\mathrm{D}$ immunoglobulin in a rhesus $\mathrm{D}(\mathrm{RhD})$-negative woman.

Objective: The aim of this study is to evaluate a direct immunofluorescence flow cytometry technique in artificial and clinical samples and compared it to the Kleihauer-Betke test (KBT).

Methods: This study was a prospective cohort design. Blood samples from 26 pregnant women who gave birth to RhD positive babies were tested using direct immunofluorescence flow cytometry and KBT techniques to determine the amount of $\mathrm{FMH}$ in the maternal circulation. The zone of D-positive cells was identified employing artificial samples including $0.3 \%$, $0.6 \%, 1 \%, 1.5 \%, 2 \%, 5 \%, 10 \%$, and $50 \%$ of D-positive fetal cells in D-negative maternal cells.

Results: Analysis of 26 clinical samples for FMH showed consistent quantification with the flow cytometry and Kleihauer techniques. Although a good correlation was found between the KBT and flow cytometry results, in artificial samples containing more than $2 \%$ of fetal RhD positive cells, the flow cytometry results were closer to theoretical percentages. In a patient with $\mathrm{FMH}>4 \mathrm{~mL}$, the $\mathrm{FMH}$ and consequently the required vial of Ig were overestimated using KBT.

Conclusion: Most of the FMH calculated could have been neutralized by doses less than $625 \mathrm{IU}$, whereas the routine dose in Iran is more than double that amount (1500 IU). This achievement demonstrates that adjusting between the RhD immune globulin (RhDIg) dose and FMH size is inevitable.

Keywords: Fetomaternal Transfusion, Rho (D) Immune Globulin, Flow Cytometry, Pregnancy, Fetus, Rh Blood-Group System
\end{abstract}

\section{Background}

In the $\mathrm{Rh}$ (rhesus)blood group system, the $\mathrm{RhD}$ antigen is the most immunogenic antigen on the surface of human red blood cells (RBCs). It is an approximately $30 \mathrm{KD}$ integral RBC membrane protein encoded by the RHD gene. This gene is located on chromosome 1p34-p36. ${ }^{1-6}$ Although most of the Iranian population carry the RHD gene ( $R$ hD positive individuals), about $10.08 \%$ of them have complete deletion of this gene ( $\mathrm{RhD}$ negative individuals), and the immune systems of this group could develop specific antibodies against the $\mathrm{RhD}$ antigen if exposed to $\mathrm{RhD}$ positive RBCs. ${ }^{7}$ This special situation could occur in pregnancy. Fetal RBCs can enter maternal circulation and RhD incompatibility with maternal blood could stimulate the production of anti-RhD antibodies in $\mathrm{RhD}$-negative women who carry $\mathrm{RhD}$-positive fetuses. In the next pregnancy, these antibodies cross the placenta into the fetal circulation and destroy the fetal RBCs, leading to hemolytic disease in the fetus and newborn (HDFN). ${ }^{1,8-10}$ RhD immune globulin (RhDIg) administration can conceal the antigenic sites of fetal RBCs and prevent the subsequent responses of the maternal immune system. ${ }^{11,12}$ Determining the fetomaternal hemorrhage (FMH) is an important factor in adjusting the dosage of RhDIg. The

Copyright (C 2018 The Author(s). This is an open-access article distributed under the terms of the Creative Commons Attribution License (http:// creativecommons.org/licenses/by/4.0), which permits unrestricted use, distribution, and reproduction in any medium, provided the original work is properly cited. 
routine policy on RhDIg administration and prescription in Iran is that all $\mathrm{RhD}$ negative women bearing $\mathrm{RhD}$ positive fetuses receive 1500 international units (IU) $(300 \mu \mathrm{g})$ of RhDIg, which is adequate for concealing up to $12 \mathrm{~mL}$ of fetal RBCs. ${ }^{13}$ The Rosette test is a traditional test that confirms the presence of fetal RBCs in maternal circulation, but gives no information about the size of the FMH. ${ }^{14-16}$ Although the Kleihauer-Betke test (KBT) quantifies the $\mathrm{FMH}$, it has some disadvantages. This test is based on the resistance of fetal hemoglobin to acid elution. KBT is inexpensive and performed with basic laboratory equipment, but the sensitivity of the test is affected by many factors during all steps, including film preparation, staining, elution, and interpretation of the stained blood films. ${ }^{17-21}$ The flow cytometric (FC) technique is the most recent method that can evaluate fetal RhD RBCs in maternal blood by means of monoclonal antibodies against fetal markers like hemoglobin $\mathrm{F}(\mathrm{HbF})$ or surface $\mathrm{RhD}$ antigens. ${ }^{22,23}$

\section{Objective}

In this study, an EC method for quantitating fetal $\mathrm{RhD}$ RBCs in comparison with the Kleihauer technique was assessed in both artificial and clinical samples. Fluorescein isothiocyanate (FITC) labeled monoclonal anti-D was used to calculate fetal RhD positive cells in maternal blood by FC.

\section{Methods}

\subsection{Sample Preparation}

\subsubsection{Clinical Samples}

In this prospective cohort study, $28 \mathrm{RhD}$ negative pregnant women were enrolled during their most recent prenatal obstetric visit at Hafez Hospital, Shiraz, Iran. The minimum sample size was calculated using MedCalc Statistical Software version 14.8.1 (MedCalc, Ostend, Belgium) based on the equation $\mathrm{N}=([\mathrm{Z} \alpha+\mathrm{Z} \beta] / \mathrm{C}) 2+3, \alpha=0.05, \beta=0.20$ and the expected correlation coefficient $(r)=0.5$. Women included in the study were $\mathrm{RhD}$ negative and had husbands who were RhD positive. Those women who had a history of any hemoglobinopathy disorders were excluded. Up to 12 hours after delivery, the peripheral blood of mothers who delivered $\mathrm{RhD}$ positive babies $(5 \mathrm{~mL}$ ) was collected in tubes with ethylenediaminetetraacetic acid (EDTA, INTERLAB Laboratory Products, Turkey), and the samples were stored at $4^{\circ} \mathrm{C}$ until processing.

\subsubsection{Spiked Samples}

Artificial samples were prepared by adding varying amounts of $\mathrm{RhD}$ positive cord blood to blood samples from $\mathrm{RhD}$ negative non-pregnant women. Different dilutions $(0.3 \%, 0.6 \%, 1 \%, 1.5 \%, 2 \%, 5 \%, 10 \%$, and $50 \%)$ of fetal RBCs in maternal RBCs were used in this study. Previously, to calculate the exact amount of cord blood to be added to adult blood, the RBC counts of both cord and adult blood were determined by an automated cell counter (Sysmex KX-21N, Japan), and the required volume of the cord RBCs to be added was calculated using the formula of the Scientific Subcommittee of the Australian \& New Zealand Society of Blood Transfusion. ${ }^{24}$

\subsection{Kleihauer-Betke Acid-Elution Test}

The KBT test was performed according to the description given by Kleihauer, Braun, and Betke in 1957 with slight modification..$^{25}$

Samples were diluted with normal saline (N/S). Thin layers of diluted blood were smeared on slides. After drying, the slides were fixed in $80 \%$ ethanol for 5 minutes and then incubated in citric-phosphate buffer ( $\mathrm{pH}: 1.5$ ) for 5 minutes at $37^{\circ} \mathrm{C}$. Staining was done by incubation in erythrosine (Merck, Germany) and hematoxylin acid (Merck, Germany) for 5 minutes, respectively. The slides were rinsed with water and dried between all steps. The fetal cells were counted microscopically using a high objective lens (40x). Malison's formula was employed to calculate the volume of $\mathrm{FMH} .^{26,27}$

\subsection{Flow Cytometry}

First, the direct flow cytometry protocol was conducted by adding different percentages of $\mathrm{RhD}$ positive cells to RhD negative blood using FITC-BRAD-3 monoclonal anti-D (Research American product, USA). Whole blood was collected in EDTA and washed twice with phosphatebuffered saline-bovine serum albumin (PBS-BSA). $10^{6}$ RBCs were separated and incubated with $2 \mu \mathrm{L}$ of FITC monoclonal anti-D for 30 minutes at $37^{\circ} \mathrm{C}$. As a negative control, unstained $\mathrm{RhD}$ positive and $\mathrm{RhD}$ negative $\mathrm{RBCs}$ were used. Flow cytometry was performed on a BD FACS Calibur (BD Bioscience, USA), and a minimum of $>50000$ events were analyzed in each experiment. RBCs were gated using logarithmic forward and side scatter (FSC/SSC), and the gated RBCs were evaluated in the FL1 channel. Data was analyzed using FlowJo 7.6 software, and the FMH was calculated as mentioned for KBT.

\subsection{Statistical Analysis}

Clinical samples were collected using the simple random sampling (SRS) method. The Pearson correlation coefficient (r) analysis was used to compare the results of KBT and flow cytometry. Statistical tests were performed at the 0.05 significance level and results of $P<0.05$ were considered significant. All statistical analyses were carried out by SPSS, version 16.0 (Ltd, Hong Kong).

\section{Results}

This study included $28 \mathrm{RhD}$ negative pregnant women. Two mothers gave birth to $\mathrm{RhD}$ negative babies and were excluded from the study. The KBT was performed at the two incubation times of $25^{\circ} \mathrm{C}$ for 10 minutes and $37^{\circ} \mathrm{C}$ for 5 minutes. The results showed more resolution between fetal and ghost adult cells at $37^{\circ} \mathrm{C}$. Thus, the clinical samples were incubated at $37^{\circ} \mathrm{C}$ for 5 minutes (Figure 1). The detection thresholds of the two methods were assessed by analyzing the artificial samples ranges between $0.3 \%$ 


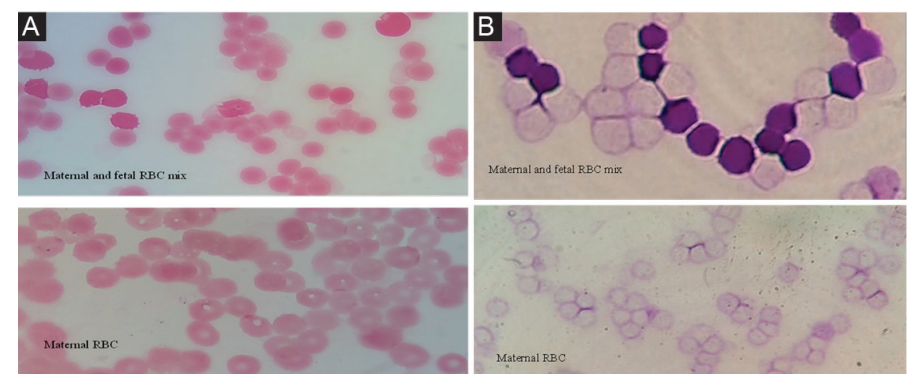

Figure 1. Comparison of the KBT Results in 2 Different Elution Temperatures: A. Elution at $25^{\circ} \mathrm{C}$ for $11 \mathrm{~min}$; B. Elution at $37^{\circ} \mathrm{C}$ for $5 \mathrm{~min}$.
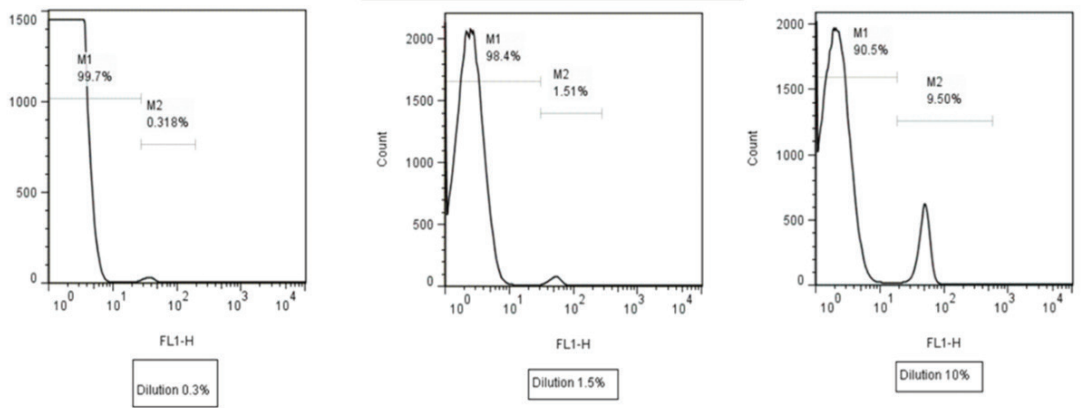

Figure 2. Fetomaternal Hemorrhage Detection Using Anti-RhD Antibody by Flow Cytometry in 3 Different Dilutions of RhD Positive RBCs in RhD Negative blood. M2 region shows the population of RhD positive cells.

and $50 \%$ of $\mathrm{RhD}$ positive cord blood in $\mathrm{RhD}$ negative maternal blood (Figure 2). Although the FMH greater than $2 \%$ were slightly overestimated by KBT (Table 1 ), the correlation between the results of various suspensions of FMH using both methods, the KBT and flow cytometry, and theoretical percentages showed that the two methods were accurate $\left(\mathrm{r}_{\mathrm{KBT}}=1.000, \mathrm{r}_{\mathrm{f}}=1.000\right.$, and $\left.P<0.05\right)$. The KBT and flow cytometry were performed on 26 clinical blood samples. Nine samples had no detectable FMH, 17 had $<4 \mathrm{~mL}$, and 2 samples had an FMH $>4 \mathrm{~mL}$. According to the results of both methods, the required vial of RhIG (625 IU) in 24 patients was the same. Although the 2 methods predicted the FMH of both high and low RhD positive cell concentrations accurately $(r=0.999, P<0.05)$, patients with $\mathrm{FMH}>4 \mathrm{~mL}$, the $\mathrm{FMH}$, and consequently the required vial of Ig were overestimated using KBT (Table 2).

\section{Discussion}

Measuring the size of the FMH after delivery, abortion, or any invasive procedures in the pregnancies of $\mathrm{RhD}$ negative women is an essential step to estimating the adequate dosage of RhDIg. In this study, the FMH volume was estimated in clinical and artificial samples by KBT and flow cytometry. Although a good correlation was found between the KBT and flow cytometry results, in artificial samples containing more than $2 \%$ of fetal $\mathrm{RhD}$ positive cells, the FMH detected using flow cytometry was lower than that estimated by the KBT. In fact, the flow cytometry results were closer to the theoretical percentages. These results are in agreement with those of Bayliss et al. They showed that there is a poor correlation between KBT and flow cytometry results in women having an FMH greater than $4 \mathrm{~mL}^{16}$

Lloyd-Eva indicated that, although flow cytometry more accurately estimated large FMHs (1-7 mL), FMHs less than $1 \mathrm{~mL}$ were quantified more accurately by KBT. ${ }^{28}$ Pelikan et al showed that flow cytometry is not sensitive enough to detect an FMH less than $0.1 \%$. Data from the clinical and artificial samples in this study did not confirm these results. ${ }^{8}$

Although most studies have used monoclonal anti-D to estimate $\mathrm{FMH}$ size, ${ }^{28,29}$ others $^{30,31}$ have employed monoclonal anti-HbF (fetal hemoglobin) to detect fetal RBCs in maternal circulation. In addition to extra steps, including cells fixation and permeabilization, the quantification of FMH using anti-HbF is less accurate compared to anti-D. Kennedy et al pointed out that large

Table 1. Estimated FMH (Volume of Fetal RBCs) and Number of RhDIg Vials Required in Clinical Samples

\begin{tabular}{lcc}
\hline $\begin{array}{l}\text { Percentage Rh D } \\
\text { Positive }\end{array}$ & KBT Result & Flow Cytometer Result \\
\cline { 2 - 3 } & Mean \pm SD & Mean \pm SD \\
\hline 50 & $52 \pm 1.2$ & $49.7 \pm 0.52$ \\
10 & $10.8 \pm 0.62$ & $9.5 \pm 0.36$ \\
5 & $6.1 \pm 0.42$ & $4.95 \pm 0.3$ \\
2 & $2.2 \pm 0.13$ & $1.96 \pm 0.10$ \\
1.5 & $1.3 \pm 0.098$ & $1.51 \pm 0.9$ \\
1 & $0.99 \pm 0.08$ & $1 \pm 0.08$ \\
0.6 & $0.58 \pm 0.06$ & $0.62 \pm 0.066$ \\
0.3 & $0.4 \pm 0.03$ & $0.32 \pm 0.025$ \\
\hline
\end{tabular}


Table 2. Results of Prepared Dilutions of RhD Positive Cells in RhD Negative Red Cells

\begin{tabular}{|c|c|c|c|c|}
\hline \multirow[b]{2}{*}{ Samples } & \multicolumn{2}{|r|}{ KBT } & \multicolumn{2}{|c|}{ FC With Anti-D } \\
\hline & $\begin{array}{r}\text { FMH } \\
(\mathrm{mL})\end{array}$ & $\begin{array}{l}\text { Vials of Anti-D Ig } \\
\text { Required (625 IU) }\end{array}$ & $\begin{array}{l}\text { FMH } \\
(\mathrm{mL})\end{array}$ & $\begin{array}{l}\text { Vials of Anti-D Ig } \\
\text { Required (625 IU) }\end{array}$ \\
\hline $1-9$ & 0 & 0 & 0 & 0 \\
\hline 10 & 0.07 & 1 & 0.09 & 1 \\
\hline 11 & 0.072 & 1 & 0.096 & 1 \\
\hline 12 & 0.24 & 1 & 0.29 & 1 \\
\hline 13 & 0.26 & 1 & 0.26 & 1 \\
\hline 14 & 0.29 & 1 & 0.3 & 1 \\
\hline 15 & 0.34 & 1 & 0.37 & 1 \\
\hline 16 & 0.67 & 1 & 0.61 & 1 \\
\hline 17 & 0.69 & 1 & 0.69 & 1 \\
\hline 18 & 0.7 & 1 & 0.59 & 1 \\
\hline 19 & 1.63 & 1 & 1.38 & 1 \\
\hline 20 & 1.68 & 1 & 1.38 & 1 \\
\hline 21 & 1.68 & 1 & 1.40 & 1 \\
\hline 22 & 1.87 & 1 & 1.58 & 1 \\
\hline 23 & 2.54 & 1 & 2.23 & 1 \\
\hline 24 & 3.12 & 1 & 2.74 & 1 \\
\hline 25 & 5.76 & 2 & 4.39 & 1 \\
\hline 26 & 10.56 & 3 & 8.34 & 2 \\
\hline
\end{tabular}

FMHs were underestimated using anti-HbF. According to Kennedy's article, the probable reason for this finding is related to fetal-to-adult hemoglobin switching. Although the expression of the $\mathrm{D}$ antigen on all erythrocytes was completed and stabilized by 6 weeks gestation, fetal-toadult hemoglobin switching begins several weeks before birth and only approximately $70 \%$ of hemoglobin in cord blood is fetal hemoglobin. ${ }^{32}$

\section{Conclusion}

Based on this study, most of the FMH calculated could have been neutralized by doses less than $625 \mathrm{IU}$, whereas the routine dose in Iran is more than double that amount (1500 IU). This achievement demonstrates that adjustment between the RhDIg dose and FMH size is inevitable. In fact, besides the cost of RhDIg, there are some concerns about the risk of viral and prion transmission through this blood product. Although the flow cytometry method using anti $\mathrm{D}$ reagent is the most reliable technique for measuring $\mathrm{FMH}$ and determining the sufficient dose of RhDIg, the KBT method could be established and employed in local hospitals.

\section{Authors' Contributions}

SD, ZK and LM: study conception and design, analysis and interpretation of the data. RR, MA and MM: sample collection, sample preparation and data collection. ZK, $\mathrm{SD}$ and $\mathrm{ABB}$ : manuscript writing and critical revision. All authors of this paper have read and approved the final version submitted.

\section{Research Highlights}

\section{What Is Already Known?}

$\mathrm{RhD}$ incompatibility between the $\mathrm{RhD}$ negative pregnant women and their $\mathrm{RhD}$ positive fetuses leads to hemolytic disease of the fetus and newborn (HDFN). In the hospitals of Iran, all these women routinely receive $300 \mu \mathrm{g}$ (1500 IU) of RhDIg.

\section{What This Study Adds?}

The current study highlights the real need for reassessment of the routine policy of RhDIg administration and prescription. Besides the cost of RhDIg, determining the FMH decreases some concerns about the risk of viral and prion transmission by this blood product. According to the current findings, measuring FMH should be an essential part of $\mathrm{RhD}$ negative women prenatal care.

\section{Conflict of Interest Disclosures}

The authors declare that they have no conflicts of interest.

\section{Ethical Approval}

The Ethics Committee of the Shiraz University of Medical Sciences approved the invasive procedure of this study (ecp-90-3311), and pregnant women who participated in this research completed the consent form consciously.

\section{Acknowledgments}

This article was extracted from the biotechnology MS thesis written by Zeinab Keshavarz and was funded by Shiraz University of Medical Sciences grant no. 90-1045-3311. The authors would like to thank the laboratory and midwifery staffs of Hafez Hospital for their earnest cooperation.

\section{References}

1. Dajak S, StefanovicV, CapkunV. Severe hemolytic disease of fetus and newborn caused by red blood cell antibodies undetected at first-trimester screening (CME). Transfusion. 2011;51(7):13801388.doi:10.1111/j.1537-2995.2010.03006.x.

2. Daniels G. The molecular genetics of blood group polymorphism. Hum Genet. 2009;126(6):729-742. doi:10.1007/s00439-0090738-2.

3. Avent ND, Reid ME. The Rh blood group system: a review. Blood. 2000;95(2):375-387.

4. Heitman J, Agre P. A new face of the Rhesus antigen. Nat Genet. 2000;26(3):258-259.doi:10.1038/81532.

5. Conroy MJ, Bullough PA, Merrick M, Avent ND. Modelling the human rhesus proteins: implications for structure and function. $\mathrm{Br}$ J Haematol. 2005;131(4):543-551. doi:10.1111/j.13652141.2005.05786.x.

6. Van Kim CL, Colin Y, Cartron JP. Rh proteins: key structural and functional components of the red cell membrane. Blood Rev. 2006;20(2):93-110. doi:10.1016/j.blre.2005.04.002.

7. Pourfathollah AA, Oody A, Honarkaran N. Geographical distribution of $\mathrm{ABO}$ and $\mathrm{Rh}(\mathrm{D})$ blood groups among Iranian blood donors in the year 1361(1982) as compared with that of the year 1380 (2001). Sci J Iran Blood Transfus Organ. 2004;1(1):11-17.

8. Pelikan DM, Scherjon SA, Mesker WE, et al. Quantification 
of fetomaternal hemorrhage: a comparative study of the manual and automated microscopic Kleihauer-Betke tests and flow cytometry in clinical samples. Am J Obstet Gynecol. 2004;191(2):551-557. doi:10.1016/j.ajog.2004.01.007.

9. Ali MS, El Amin AY, Gamal M, Abdulla N, Mohamed A. Foetal maternal haemorrhage detection with the Kleihauer technique for postnatal immunoglobulin dose evaluation in Sudan. NZ J Med Lab Science. 2005;59(1):6-9.

10. Ramsey G. Inaccurate doses of R immune globulin after rhincompatible fetomaternal hemorrhage: survey of laboratory practice. Arch Pathol Lab Med. 2009;133(3):465-469. doi:10.1043/1543-2165-133.3.465.

11. Regan F, Kumar S, Contreras M. Haemolytic disease of the newborn and its prevention. In: Contreras $\mathrm{M}$, ed. $\mathrm{ABC}$ of Transfusion. 4th ed. Chichester, UK: Wiley-Blackwell Pub; 2009:27-32

12. Crowther C, Middleton P. Anti-D administration after childbirth for preventing Rhesus alloimmunisation. Cochrane Database Syst Rev. 2000(2):Cd000021. doi:10.1002/14651858. cd000021.

13. Payam Khaja Pasha R, Shokri F. Immunologic basis and immunoprophylaxis of RhD induced hemolytic disease of the newborn (HDN). Iran J Immunol. 2008;5(4):189-200.

14. Stedman CM, Baudin JC, White CA, Cooper ES. Use of the erythrocyte rosette test to screen for excessive fetomaternal hemorrhage in Rh-negative women. Am J Obstet Gynecol. 1986;154(6):1363-1369. doi:10.1016/0002-9378(86)90725-8.

15. Sebring ES, PoleskyHF. Detection offetal hemorrhage in Rh immune globulin candidates. A rosetting technique using enzyme-treated Rh2Rh2 indicator erythrocytes. Transfusion. 1982;22(6):468471. doi:10.1046/j.1537-2995.1982.22683068604.x.

16. Bayliss KM, Kueck BD, Johnson ST, et al. Detecting fetomaternal hemorrhage: a comparison of five methods. Transfusion. 1991;31(4):303-307. doi:10.1046/j.15372995.1991.31491213292.x

17. Hoyer JD, Penz CS, Fairbanks VF, Hanson CA, Katzmann JA. Flow cytometric measurement of hemoglobin $F$ in RBCs: diagnostic usefulness in the distinction of hereditary persistence of fetal hemoglobin (HPFH) and hemoglobin S-hPFH from other conditions with elevated levels of hemoglobin F. Am J Clin Pathol. 2002;117(6):857-863. doi:10.1309/a63x-hg9tvyg2-x6tx.

18. The estimation of fetomaternal haemorrhage. BCSH Blood Transfusion and Haematology Task Forces. Transfus Med. 1999;9(1):87-92.

19. Wylie BJ, D'Alton ME. Fetomaternal hemorrhage. Obstet Gynecol. 2010;115(5):1039-1051.doi:10.1097/AOG.0b013e3181da7929.

20. Kim YA, Makar RS. Detection of fetomaternal hemorrhage. Am
J Hematol. 2012;87(4):417-423. doi:10.1002/ajh.22255.

21. Nath S, Vidyasagar D. Detection of fetomaternal hemorrhage. Indian J Pediatr. 1990;57(5):611-613. doi:10.1007/ BF02728698.

22. Kumpel BM. Analysis of factors affecting quantification of fetomaternal hemorrhage by flow cytometry. Transfusion. 2000;40(11):1376-1383. doi:10.1046/j.15372995.2000.40111376.x.

23. Porra V, Bernaud J, Gueret $P$, et al. Identification and quantification of fetal red blood cells in maternal blood by a dual-color flow cytometric method: evaluation of the Fetal Cell Count kit. Transfusion. 2007:47(7):1281-1289. doi:10.1111/ j.1537-2995.2007.01271.x

24. Woodfield G, Davis K, Francis A, et al. Guidelines for laboratory assessment of fetomaternal haemorrhage. Sydney: Australian and New Zealand Society of Blood Transfusion Inc; 2002.

25. Kleihauer E, Braun $H$, Betke K. [Demonstration of fetal hemoglobin in erythrocytes of a blood smear]. Klin Wochenschr. 1957;35(12):637-638. doi:10.1007/BF01481043.

26. Mollison PL. Quantitation of transplacental haemorrhage. Br Med J. 1972;3(5817):31-34. doi:10.1136/bmj.3.5817.31

27. Austin E, Bates S, de Silva M, et al. Working Party of the British Committee for Standards in Haematology, Transfusion Taskforce. Guidelines for the Estimation of Fetomaternal Haemorrhage; 2009.

28. Lloyd-Evans P, Kumpel BM, Bromelow I, Austin E, Taylor E. Use of a directly conjugated monoclonal anti-D (BRAD-3) for quantification of fetomaternal hemorrhage by flow cytometry. Transfusion. 1996;36(5):432-437. doi:10.1046/j.15372995.1996.36596282587.x.

29. Nelson M, Zarkos K, Popp H, Gibson J. A flow-cytometric equivalent of the Kleihauer test. Vox Sang. 1998;75(3):234241. doi:10.1046/j.1423-0410.1998.7530234.x.

30. Davis BH, Olsen S, Bigelow NC, Chen JC. Detection of fetal red cells in fetomaternal hemorrhage using a fetal hemoglobin monoclonal antibody by flow cytometry. Transfusion. 1998;38(8):749-756. doi:10.1046/j.1537-2995.1998.38898375514.x.

31. Davis B, Olsen S, Bigelow N, Chen J. Detection of fetal red cells in fetomaternal hemorrhage using a fetal hemoglobin monoclonal antibody by flow cytometry. Obstet Gynecol Surv. 1999;54(3):153-154. doi:10.1097/00006254-19990300000004.

32. Kennedy GA, Shaw R, Just $S$, et al. Quantification of fetomaternal haemorrhage $(\mathrm{FMH})$ by flow cytometry: anti-fetal haemoglobin labelling potentially underestimates massive FMH in comparison to labelling with anti-D. Transfus Med. 2003;13(1):25-33. doi:10.1046/j.1365-3148.2003.00416.x. 